\title{
Analysis of Interfacial Microsstructure of Post Weld Heat Treated Dissimilar Metal Weld of Type 316LN/C-Steel Joint
}

\author{
K. Jithendar Reddy ${ }^{1}$, M. Manzoor Hussain ${ }^{2}$, Sujith Sathyan ${ }^{3}$ and \\ G. Gopala Krishna ${ }^{4}$ \\ ${ }^{l}$ Associate Professor, Mechanical Engineering Department, J.B.Instritute of Engineering \& Technology(Autonomous), \\ Moinabad, Hyderabad - 500 075, AP, India. \\ ${ }^{2}$ Principal, JNTUH College of Engineering, Sulthanpur, Medak Dist, AP, India. \\ ${ }^{3}$ Scientific Officer, Indhira Gandhi Center for Atomic Research, Kalpakkam - 603102. \\ ${ }^{4}$ Associate Professor, Mechanical Engineering Department, J.B.Instritute of Engineering \& Technology, Moinabad, \\ Hyderabad-500 075.
}

\begin{abstract}
In Prototype Fast Breeder Reactor (PFBR), the main vessel which contains the primary sodium and supports the core is suspended from the roof slab. The materials for construction for main vessel and roof slab are type 316LN austenitic stainless steel and Carbon steel of grade A48P2, respectively. As the materials of construction are different, a transition joint between austenitic stainless steel and C-steel is necessary. In this investigation the effect of post-weld heat treatment (PWHT) on the interfacial microstructure of as-welded and PWHTed type 316LN/C-steel joint welded with Inconel 182 was investigated. These joints were PWHTed to various temperatures between 898 to $973 \mathrm{~K}$ for $1 \mathrm{~h}$ and results were evaluated. From the above results, different methods to temper the martensitic structure or to change to an equilibrium structure without PWHT are also presented.
\end{abstract}

Keywords: Post Weld Heat Treatment (PWHT), Interfacial Microstructure, $316 L N$ austenitic stainless steel and Carbon steel of grade A48P2.

\section{INTRODUCTION}

In PFBR, the main vessel which contains the primary sodium and supports the core is suspended from the roof slab. The materials for construction for main vessel and roof slab are type $316 \mathrm{LN}$ and C-steel of grade A48P2 respectively. As the materials of construction are different a transition joint between austenitic stainless steel and C-steel is necessary. Such a joint is often welded by gas tungsten arc welding or manual metal arc welding processes. There is no particular demand arising from corrosion aspects; since corrosion resistance of $\mathrm{C}$-steel is extremely poor.

It is reported [1] that, a transition joint between austenitic stainless steel to C-steel can be made by different ways; either using nickel base welding consumable or by austenitic stainless steel welding consumable. Further, a buffer layer with Ni-base consumables of 3-4 mm thick on C-steel is necessary prior to welding with austenitic stainless steel consumables. General trend is to heat treat the buttered layer to the requisite temperature and then do welding on the austenitic stainless steel consumable without any pre/post heat treatment. The embrittlement effect produced by delta phase precipitation in austenitic stainless steel weld metal mainly affects the impact toughness of austenitic weld metal. In case of transition joints which are made with Ni-base welding consumables (without buffer layer) post weld heat treatment can be followed after completion of the welding operation. High impact toughness properties of the weld metal and the transition zone, after annealing of such joint is reported [2]. Also the C-migration from C-steel HAZ to weld metal (Ni-base) is lower than that of austenitic weld metal, since C-activity difference is lower. However, major difficulties are experienced during welding operation. For example, C-steels require controlled pre/post thermal treatments to temper the martensite or stress relieve the residual stresses. Austenitic stainless steel base metal on the other hand does not require any pre/post weld heat treatments. The contradicting requirements of this transition joint make the welding process extremely difficult.

The buttering layer which is deposited on the low alloy steel side should be deposited using smaller diameter electrodes in combination with lower heat input. Further, in some cases buttering is carried out using gas tungsten arc welding processes. However, in the above cases, welding operation needs more number of passes and thus the welding operation need more time. The only drawback of Ni-base weld metal is their inferior weldability compared to that of austenitic stainless steel consumables. But stringent control over S \& $\mathrm{P}$ in Ni-base consumables will offer better weldability compared to that of austenitic stainless steel consumables. Further, the economics of Ni-base consumables also comes into picture when welding larger section. Other problem relating buttering is that the subsequent passes made by austenitic consumables should have greater overlapping. It is also recommended to prepare a groove geometry after the buffer layer is made. 
This work reports and discusses the results of the investigation on the effect of PWHT which is essential to temper hard, brittle martensite in the HAZ of C-steel on the microstructure of weld metal/C-steel interface in the as-welded and PWHTed conditions.

\section{Welding of Type 316LN Stainless Steel to Carbon Steel \\ II. Experimental Procedure}

Single V-groove butt joints were prepared by welding $12 \mathrm{~mm}$ thick plates of $316 \mathrm{LN}$ austenitic stainless steel in the solution annealed condition and carbon steel by using Inconel 82/182 welding consumables. The chemical composition of the weld metal and the base metal is given in Table 1. The gas tungsten arc welding (GTAW) process was used for the first two root passes and the shielded metal arc welding (SMAW) process was used for the subsequent passes. The plates were set up in the flat $(1 \mathrm{G})$ position and the length and width of each weld pad was 500 and $250 \mathrm{~mm}$ respectively. The weld joint design is given in Fig. 1, while the details of welding conditions used are given in Table 2.

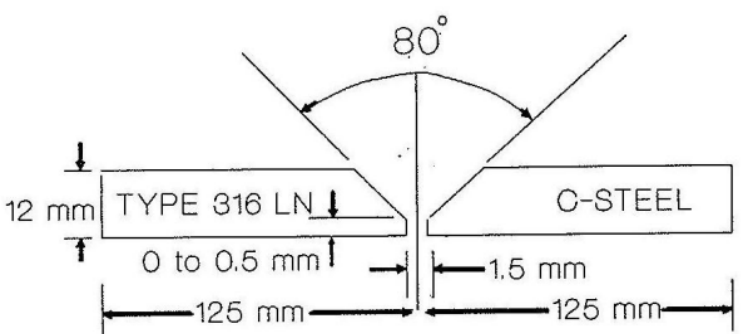

Fig .1.Schematic of weld joint design used

Dye-penetrant test was carried out for the root passes on completion of welding. The completed welds were tested by X-radiography, using a $2 \%$ penetrameter standard. Before preparation of specimens for microstructure analysis, the root region of the weld pads were completely machined off to ensure that the weld metal consisted entirely of the SMAW viz. Inconel 182.

These weld pads were then used to study the effects of PWHT on the interfacial microstructure of carbon steel, for choosing its optimum PWHT. The details of the experimental procedures are given in the following sections.

\begin{tabular}{|c|c|c|c|c|}
\hline Element & 316LN SS & $\begin{array}{c}\text { Inconel 82 } \\
\text { Weld metal }\end{array}$ & $\begin{array}{c}\text { Inconel 182 } \\
\text { Weld metal }\end{array}$ & $\begin{array}{c}\text { Carbon } \\
\text { Steel }\end{array}$ \\
\hline $\mathrm{C}$ & 0.03 & 0.015 & 0.05 & 0.202 \\
\hline $\mathrm{Si}$ & 0.35 & 0.13 & 0.56 & $*$ \\
\hline $\mathrm{Mn}$ & 1.72 & 2.78 & 7.84 & $* .56$ \\
\hline $\mathrm{P}$ & 0.023 & 0.01 & 0.01 & 0.018 \\
\hline $\mathrm{S}$ & 0.001 & 0.003 & 0.004 & -- \\
\hline $\mathrm{Cr}$ & 17.2 & 19.6 & 13.8 & -- \\
\hline $\mathrm{Ni}$ & 12.1 & 72.6 & 66.2 & -- \\
\hline $\mathrm{Mo}$ & 2.55 & -- & -- & -- \\
\hline $\mathrm{A} 1$ & -- & 0.01 & 0.40 & -- \\
\hline $\mathrm{Ti}$ & -- & 0.37 & 1.84 & -- \\
\hline $\mathrm{Nb}$ & -- & 2.68 & -- & -- \\
\hline $\mathrm{V}$ & -- & -- & -- & -- \\
\hline $\mathrm{Cu}$ & 0.16 & -- & -- & -- \\
\hline $\mathrm{Co}$ & 0.15 & -- & -- & Balance \\
\hline $\mathrm{B}$ & 0.0001 & -- & -- & - \\
\hline $\mathrm{N}$ & 0.07 & -- & 7.58 & \\
\hline $\mathrm{Fe}$ & Balance & 0.6 & & \\
\hline
\end{tabular}

* not determined

Table 1: Chemical compositions of materials used (wt\%) 


\begin{tabular}{|c|c|c|}
\hline & $1^{\text {st }}$ two root passes & Subsequent passes \\
\hline Welding process & GTAW & SMAW \\
\hline Welding consumables & Inconel 82 & Inconel 182 \\
\hline Consumable specification & $\begin{array}{c}\text { ERNiCr-3 } \\
\text { (AWS 5.14) }\end{array}$ & $\begin{array}{c}\text { ENiCrFe-3 } \\
\text { (AWS 5.14) }\end{array}$ \\
\hline Consumable diameter $(\mathrm{mm})$ & 1.6 & 2.4 \\
\hline Welding position & $1 \mathrm{G}$ (Flat) & $1 \mathrm{G}$ (Flat) \\
\hline Welding speed $(\mathrm{mm} / \mathrm{min})$ & $45-70$ & 180 \\
\hline Polarity & DCEN & DCEP \\
\hline Welding current (Amps) & $100-125$ & $100-125$ \\
\hline Arc voltage (volts) & 20 & 20 \\
\hline Preheat temperature $(\mathrm{K})$ & 423 & 423 \\
\hline Inter Pass Temperature $(\mathrm{K})$ & 423 & 423 \\
\hline
\end{tabular}

Table 2: Welding Conditions Used

\section{Post-Weld Heat Treatments}

For studying the effects of PWHT the weld joints were first subjected to $1 \mathrm{~h}$ PWHT at four different temperatures, viz. 898, 923, 948 and $973 \mathrm{~K}$.

\section{Metallography}

Transverse-weld sections of the all PWHTed weld joints were cut and metallographically polished. They were then etched with $2 \%$ Nital reagent (composition: $2 \mathrm{ml}$ nitric acid, $98 \mathrm{ml}$ methanol) to reveal the microstructure on the carbon steel side. These samples were then examined by optical microscope to study the microstructure at the weld/carbon steel interface.

\section{Results And Discussion}

The microstructure of the parent $\mathrm{C}$-steel plate consists of ferrite and carbides, shown in Fig. 2. The microstructure of the weld metal (Inconel 182)/C-steel interface in the as-welded condition is shown in Fig. 3(ac). Photomicrographs have been taken from three different regions. Fig. 3(a) shows photomicrograph corresponding to the weld/base metal interface of the last pass of SMAW (named top) from the transverse specimen. Fig. 3(b) shown the interface from the centre region of the transverse weld specimen. Earlier micro structural studies on bead-on-plate welds by autogeneous welding process shows martensite in the HAZ of the C-steel. Many studies have reported white etching band of martensite [3] on the interfacial band. However, no such light etching band of martensite was observed. It is also seen that, in all the cases, the fusion line is very sharp and clean due to compositional mismatch. Figure 3(a) also shows that, the structure comprises of mostly martensite. Figure 3(c) shows photomicrograph which is taken some distance away from the fusion line towards base metal side. Untempered martensite within prior austenitic grain is clearly visible.

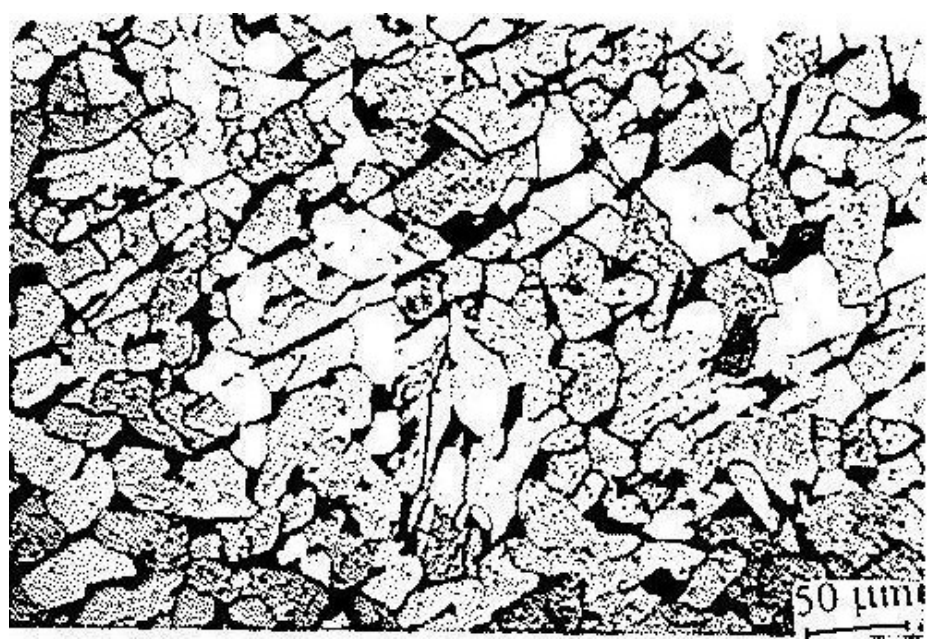

Fig. 2. Optical photo-micrograph of carbon steel base metal. 

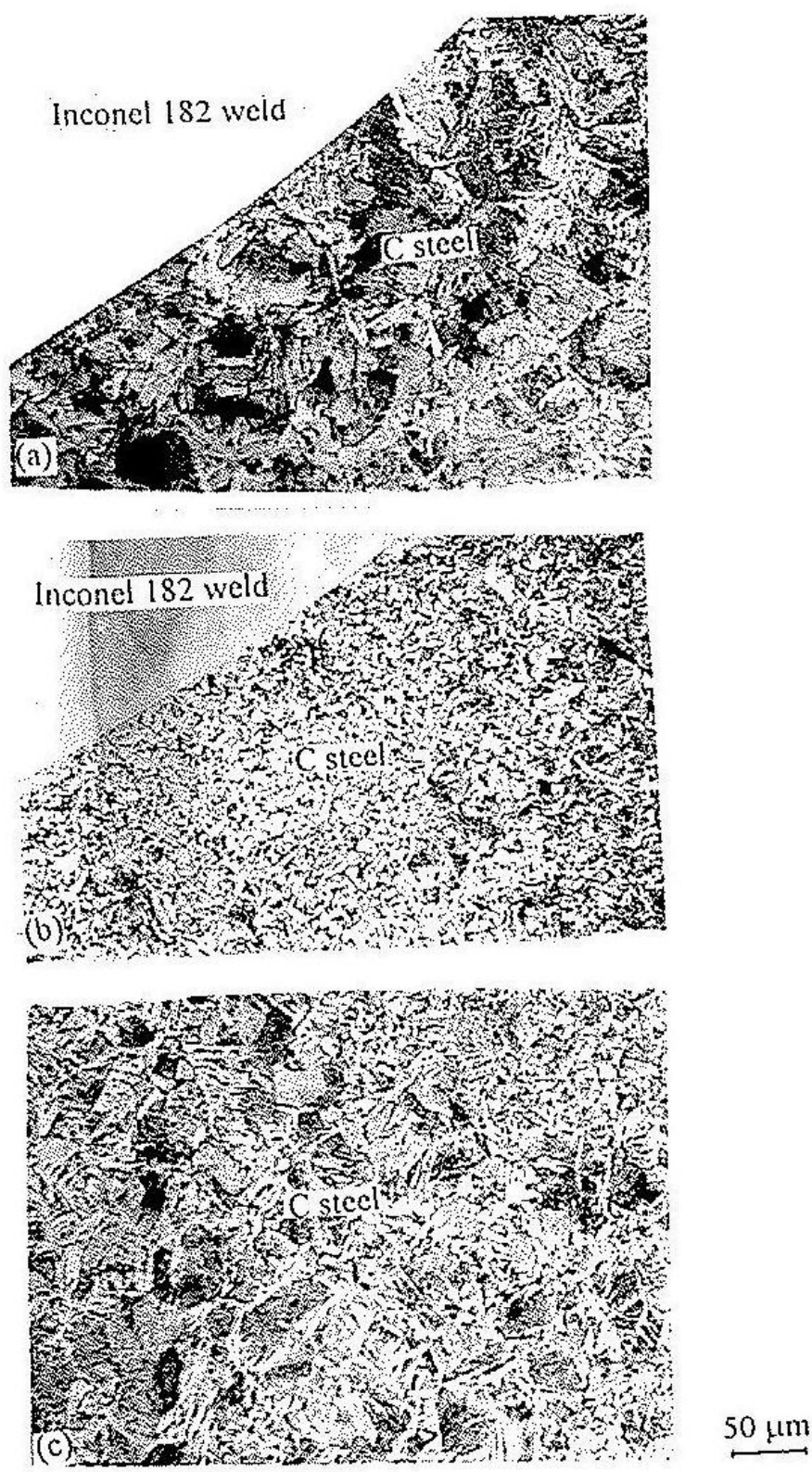

Fig. 3 Optical micrographs in the as-welded condition

a) Interface between Inconel 182 weld metal and carbon steel, at the top of the joint

b) Interface, at the centre of the joint

c) HAZ, away from the fusion line

Figure 3(b) shows photomicrograph of the interface taken from centre of the weld in the as-welded condition. The structure constitutes mostly ferrite and carbides. It is in contrast with earlier studies [4] on single bead-on-plate welds where structure is mostly martensite (shown in Figure 4). Since, in the case of multipass welding, the structure of martensite gets tempered to a certain extent [5] . In contrast to the above, here the martensite structure has completely changed into ferrite and carbides.

The microstructure of the weld metal (Inconel 182)/C-steel microstructure after the post weld heat treatments is shown in Fig. 5(a-d). It is observed that after heat treating at $898 \mathrm{~K}$ for 1h (Fig. 5(a)), the weld metal/C-steel interface consists of a dark etching interfacial band. The band is mostly due to carbides. The thickness of the dark etching band increases initially with PWHT temperature and then reduces at higher PWHT temperature. Further, in the as-welded condition, no such dark etching band is observed. The structure of C-steel HAZ is mostly ferrite and carbide in all the cases. Figure 5(c) i.e., PWHTed at 948K lh also shows structure more or less similar to that in Fig. 5(a). 


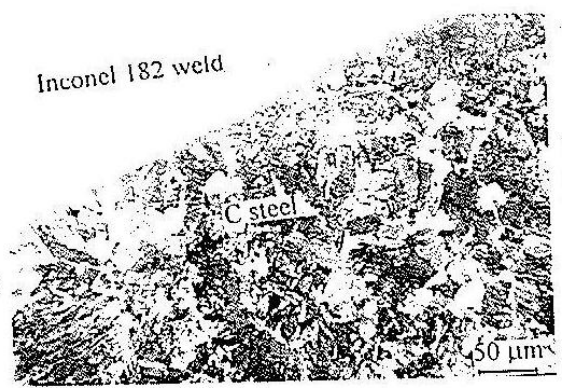

Fig.4. Optical photo-micrograph of weld metal (Inconel 182) / Carbon steel interface taken from bead-on-plate weld
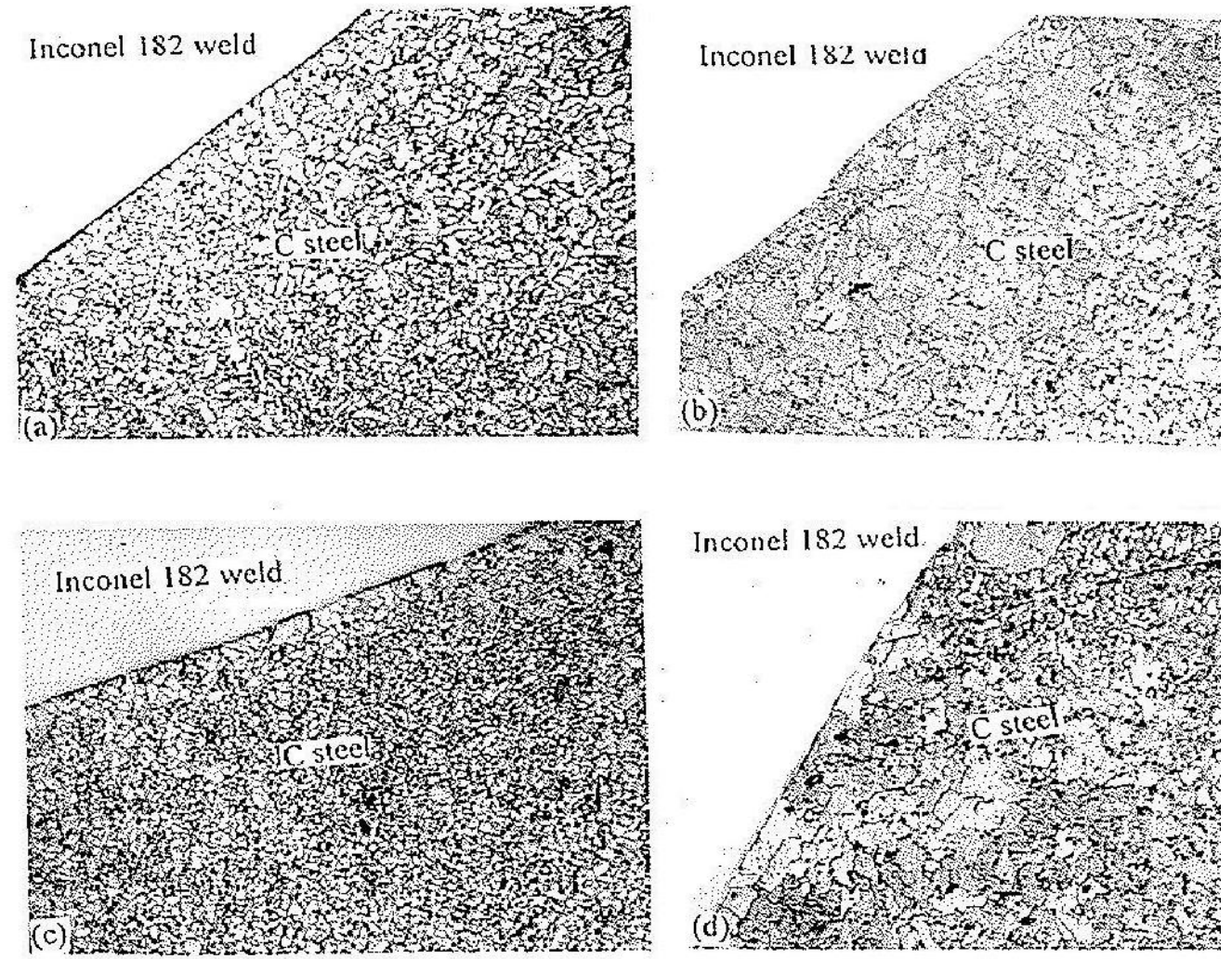

50 +เ57?.

Fig.5. Optical photomicrograph of interface between Inconel182 weldmetal and carbon steel after post weld heat treatment at (a) $898 \mathrm{~K}$ for $1 \mathrm{~h} \mathrm{(b)} 923 \mathrm{~K}$ for $1 \mathrm{~h} \mathrm{(c)} 948 \mathrm{~K}$ for $1 \mathrm{~h} \mathrm{(d)} 973 \mathrm{~K}$ for $1 \mathrm{~h}$

However, PWHTed 973K/lh (Fig. 5(d)) shows recrystallized grain in the HAZ of C-steel. In contrast with other PWHTed condition, the carbide precipitation at the interface has not been observed to any great extent.

\section{Conclusions}

Post-weld heat treatment is normally employed to reduce or eliminate residual stresses generated after welding. British Standard BS 5500, ANSI B31.3 and BS 3351 specify a PWHT temperature in the range of 923$1023 \mathrm{~K}$ for medium carbon steels. PWHT is carried out to temper the hard martensitic/bainitic structure in the $\mathrm{HAZ}$ and also to redistribute the residual stresses. Moreover, when the transition joints involving alloys having different CTE are subjected to PWHT, complete stress relief is not obtained. This is because of regeneration of stresses at the interface due to difference in the coefficients of thermal expansion while cooling the joint from PWHT temperature to ambient temperature. Hence, the benefits derived from PWHT are not fully achieved.

In this study, a transition joint between austenitic stainless steel of type $316 \mathrm{LN}$ and $\mathrm{C}$ steel is made using Inconel 182 electrodes and subsequently post weld heat treatment is carried out. From the microstructural studies of the transition joint it is observed that, Martensite is formed in the HAZ of C steel with autogeneous welding process. Moreover, in multipass welding process, the martensite has changed into an equilibrium 
structure of ferrite and carbides. Further, a martensitic structure appeared in the region where last pass of welding is made. Precipitation of carbides at the weld/C-steel interface is observed with PWHT.

\section{References}

[1] G.faber,T.Gooch, "Welded joints between stainless and low alloy steels :current position”, Welding in the world vol.20, no.5/6, 1982, pp.3-10

[2] Elmer J.W., Olson D.L., and Matlock D.K., "The thermal expansion characteristics of stainlees steel weld metal "Weld J., 61(1982) 293s-301s.

[3] A.K.Bhaduri, "Metallurgical studies for the development, characterization and evaluation of an improved transition meatal joint for steam generators", Ph.D.Thesis, Ind. Inst.Technol. Kharagpur(1990).

[4] S.K.Albert, T.P.S.Gill, A.K.Tyagi, S.L.Mannan and P.Rodriguez, "Soft zone formation in dissimilar metal welds" (Conf. Proc) Welding in power plants, 1994, P.25-37.

[5] J.F.King, M.D.Sullivan and G.M.Slaughtrer, "Development of an improved stainless steel to ferritic steel transition joint", Welding journal, pp.354-358 (1977).

[6] Bailey N. "Review of metallurgical problems in dissimilar metal welding", In . Proc. Welding Inst .Conf. Welding Dissimilar Metals, ed. N.Bailey, Cambridge, 1986, pp.1-6. 